OPEN ACCESS

Edited by:

Guoxiu Wang,

University of Technology Sydney,

Australia

Reviewed by:

Li Wang,

Tsinghua University, China

Branimir Nikola Grgur,

University of Belgrade, Serbia

*Correspondence:

Shyue Ping Ong

ongsp@eng.ucsd.edu

Specialty section:

This article was submitted to

Energy Storage,

a section of the journal

Frontiers in Energy Research

Received: 01 February 2016

Accepted: 04 April 2016

Published: 21 April 2016

Citation:

Radhakrishnan B and Ong SP (2016)

Aqueous Stability of Alkali Superionic

Conductors from First-Principles

Calculations.

Front. Energy Res. 4:16.

doi: 10.3389/fenrg.2016.00016

\section{Aqueous Stability of Alkali Superionic Conductors from First-Principles Calculations}

\author{
Balachandran Radhakrishnan and Shyue Ping Ong* \\ Department of NanoEngineering, University of California San Diego, La Jolla, CA, USA
}

Ceramic alkali superionic conductor solid electrolytes (SICEs) play a prominent role in the development of rechargeable alkali-ion batteries, ranging from replacement of organic electrolytes to being used as separators in aqueous batteries. The aqueous stability of SICEs is an important property in determining their applicability in various roles. In this work, we analyze the aqueous stability of twelve well-known Li-ion and $\mathrm{Na}$-ion SICEs using Pourbaix diagrams constructed from first-principles calculations. We also introduce a quantitative free-energy measure to compare the aqueous stability of SICEs under different environments. Our results show that though oxides are, in general, more stable in aqueous environments than sulfides and halide-containing chemistries, the cations present play a crucial role in determining whether solid phases are formed within the voltage and $\mathrm{pH}$ ranges of interest.

Keywords: superionic conductors, Pourbaix diagrams, aqueous stability, passivation, corrosion

\section{INTRODUCTION}

Ceramic alkali superionic conductor solid electrolytes (SICEs) are key enablers to new rechargeable alkali-ion battery architectures that can significantly outperform today's Li-ion batteries (Goodenough et al., 1976; Aono et al., 1990; Kanno et al., 2000; Mizuno et al., 2005; Murugan et al., 2007; Kamaya et al., 2011; Rao and Adams, 2011; Rangasamy et al., 2012). SICEs are non-flammable and may potentially support wider electrochemical windows, leading to enhanced safety and higher energy densities compared to traditional liquid organic solvent electrolytes (Xu, 2014). A good SICE must satisfy many properties, namely, excellent alkali ionic conductivity, a wide electrochemical window and interfacial stability, mechanical compatibility with the electrodes, and phase and aqueous stability. Though properties other than ionic conductivity have not received as much attention in the past, there have been several recent efforts aimed at addressing other properties such as elastic properties (Deng et al., 2016) and electrochemical stability (Zhu et al., 2015; Richards et al., 2016) that have arguably become a more critical bottleneck in SICE design than ionic conductivity.

The aqueous stability of SICEs is also important in all-solid state batteries. In the event of mechanical abuse (Doughty and Pesaran, 2012), the SICE is exposed to environmental elements. On such exposures, the SICEs can react with moisture in the air to either form passivating layers that could alter their ionic conductivity or form hazardous materials. SICEs can also be used as separators between electrodes and electrolytes in aqueous batteries (Luo et al., 2010; Ma et al., 2015). In particular, separators are necessary when Li metal is used as an anode, for example, in Li-air systems (Visco and Chu, 2000; Liu et al., 2015), as Li reduces most electrolytes on contact. Separators in such 
applications must be stable against Li metal as well as aqueous electrolytes of varying $\mathrm{pH}$ values. In particular, the NAtrium SuperIonic CONductor (NASICON), such as $\mathrm{Li}_{1.4} \mathrm{Al}_{0.4} \mathrm{Ti}_{1.4} \mathrm{Ge}_{0.2}$ $\left(\mathrm{PO}_{4}\right)_{3}$ and garnet-type SICEs, have shown great promise in such roles (Zhang et al., 2008; Imanishi et al., 2014).

Determination of the aqueous stability of solid electrolytes has thus far been predominantly based on experimental observations. Such experiments take anywhere between a week to a month (Fuentes et al., 2001), where the electrolyte is immersed in an aqueous solution, sometimes with $\mathrm{LiOH}, \mathrm{LiCl}$, etc. (Hasegawa et al., 2009; Imanishi et al., 2014), and tested for changes in surface morphology, chemistry, and ionic conductivity. These experiments are time-consuming as well as limited in the set of environmental elements that can be tested. Also, typical experiments are performed at $0 \mathrm{~V}$ vs. the standard hydrogen electrode (SHE) and do not reflect the environment that the electrolyte is exposed during battery operation.

In this work, we apply and extend the Pourbaix diagram formalism developed by Persson et al. (2012) to develop a quantitative measure of the aqueous stability of solid electrolytes based on the free-energy change and the phase of the products formed. We then apply this methodology to twelve well-known SICEs that are of current interest. Unsurprisingly, we find that oxide SICEs are significantly more stable than sulfide and halide-containing
SICEs. However, we also find wide variations in aqueous stability even within the same anion chemistry. We will discuss these findings in context of the various potential applications of SICEs in energy storage.

\section{MATERIALS AND METHODS}

To keep the discussion self-contained, we provide a brief description of the equations used in plotting the aqueous stability plots here, and interested readers are referred to the previous work of Persson et al. (2012) for more details. For a given material, operating under an externally applied potential, $V_{\text {ext }}$, the chemical reaction with an aqueous medium can be represented by the following equation:

$$
[\text { Mat }]+\mathrm{H}_{2} \mathrm{O} \stackrel{\mathrm{V}_{\text {ext }}}{\Leftrightarrow}[\operatorname{Prod}]+\mathrm{mH}^{+}+\mathrm{ze}^{-}
$$

From the Nernst equation, we can then derive the free-energy change as follows:

$$
\begin{aligned}
\Delta G_{r x n}= & \Delta G_{r x n}^{o}+2.303 \times R T \times \log \frac{[\text { Prod }]}{[\text { Mat }]} \\
& -2.303 \times R T \times m \times p H-z \mathrm{~V}_{\mathrm{ext}},
\end{aligned}
$$

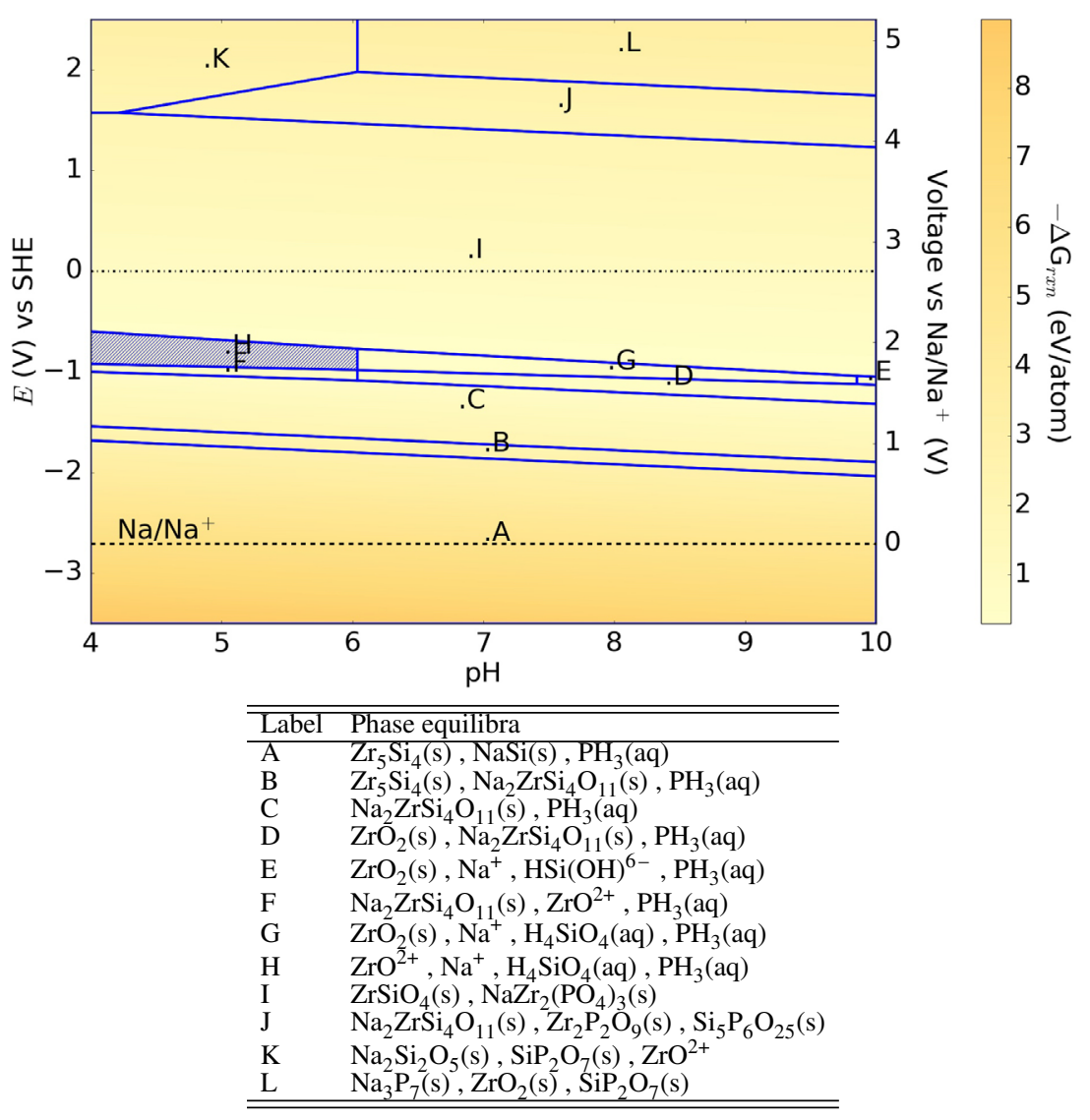

FIGURE 1 | Pourbaix diagram of $\mathrm{Na}_{3} \mathbf{Z r}_{2} \mathbf{S i}_{2} \mathbf{P O}_{12}$. Shaded region indicates absence of any solid phase products. 


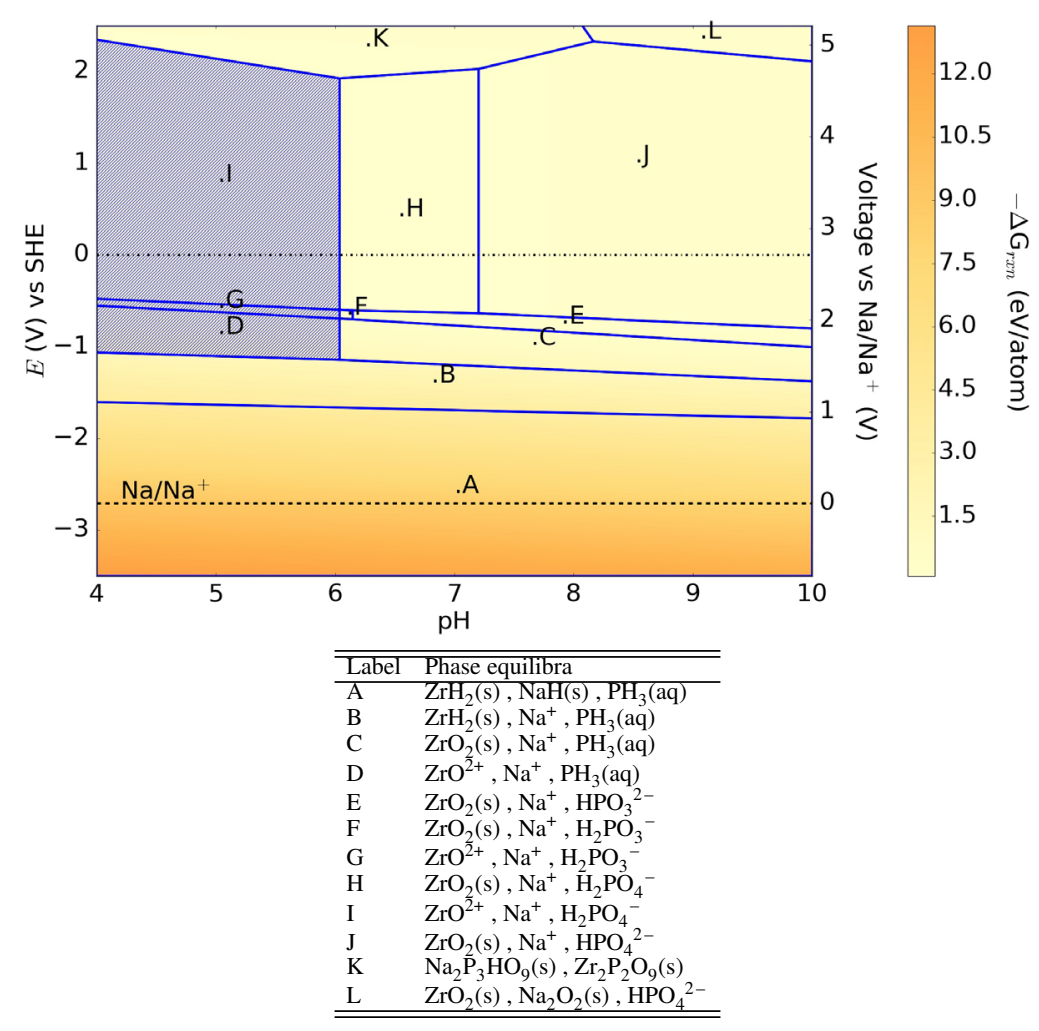

FIGURE 2 | Pourbaix diagram of $\mathrm{NaZr}_{2}\left(\mathbf{P O}_{4}\right)_{3}$. Shaded region indicates absence of any solid phase products.

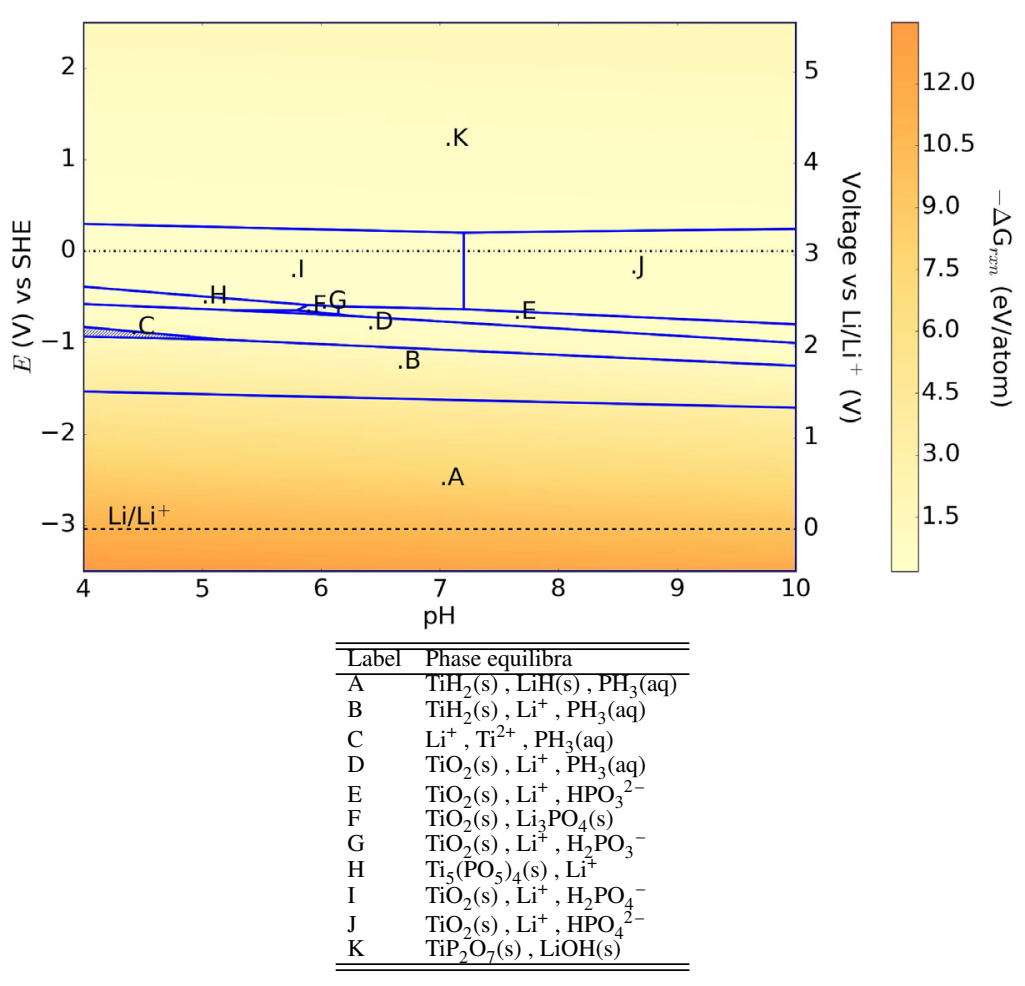

FIGURE 3 | Pourbaix diagram of $\mathrm{LiTi}_{2}\left(\mathbf{P O}_{4}\right)_{3}$. Shaded region indicates absence of any solid phase products. 


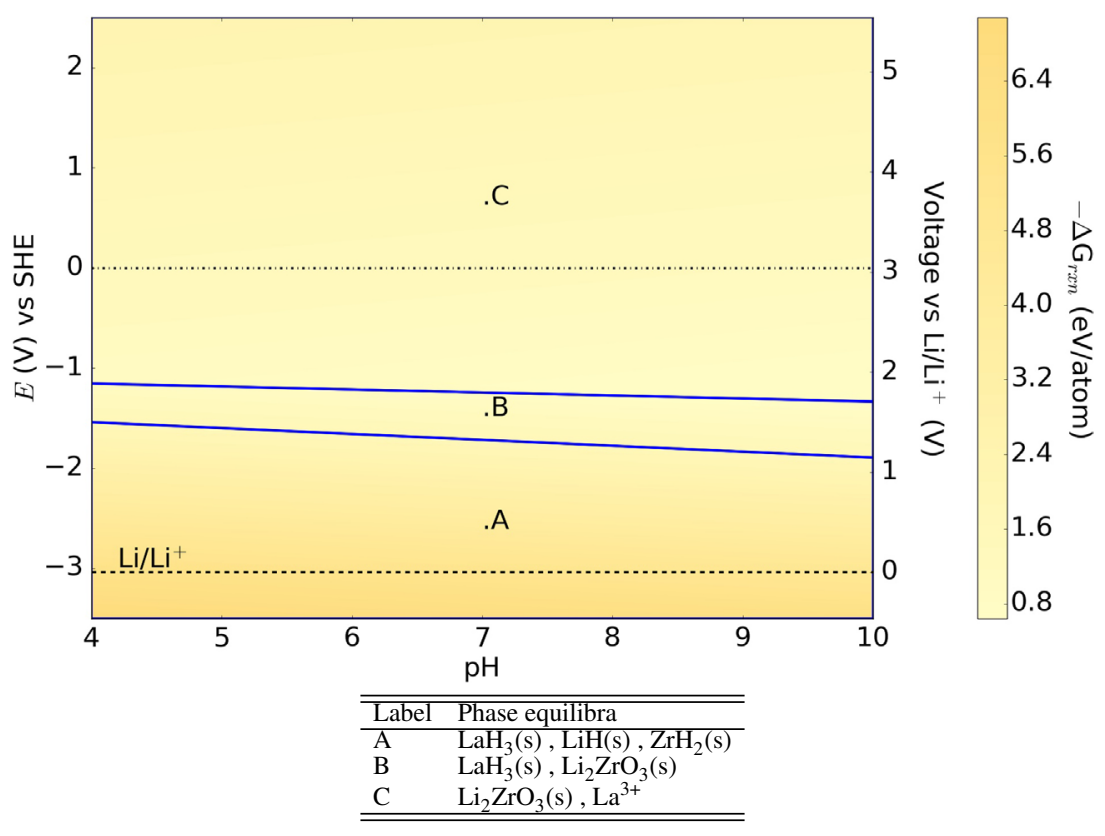

FIGURE 4 | Pourbaix diagram of $\mathrm{Li}_{7} \mathrm{La}_{3} \mathrm{Zr}_{2} \mathrm{O}_{12}$.

where, $\Delta G_{r x n}^{o}=G_{P r o d}^{o}-G_{M a t}^{o}$ is the free-energy change in the reaction under ideal environments (1 molar concentrations and $\left.\mathrm{V}_{\text {ext }}=0 \mathrm{~V}\right), R$ is the Universal gas constant, $T$ is the temperature $(=298 \mathrm{~K}), \mathrm{pH}\left(=-\log \left[\mathrm{H}^{+}\right]\right)$is the measure of acidity of the aqueous medium, and [Mat] and [Prod] represent the concentration of the chemical species involved in the reaction. The activity of $\mathrm{H}_{2} \mathrm{O}$ is assumed to be 1 . In our analysis, we use $-\Delta G_{r x n}$ as a quantitative measure of aqueous stability of the material. The larger the value of this free-energy change, the greater is the thermodynamic driving force for the reaction to occur.

All first principles calculated energies are obtained with the Vienna $A b$ initio Simulation Package (VASP) (Kresse and Furthmüller, 1996) implementation of density functional theory (DFT), using the Perdew-Burke-Ernzerhof (PBE) generalized gradient approximation (Perdew et al., 1996) description of the exchange-correlation energy. The calculation parameters are similar to those used in the Materials Project (Jain et al., 2013), and all analyses were performed using the Python Materials Genomics package (Ong et al., 2013).

As per the formalism proposed by Persson et al. (2012), the reference energies for $\mathrm{O}_{2}$ gas and $\mathrm{H}_{2} \mathrm{O}$ are fitted to experimental values (Kubaschewski et al., 1993), and the $\mathrm{H}_{2}$ energy is fixed to reproduce the $\mathrm{H}_{2} \mathrm{O}$ formation energy. The free energies of aqueous ions were calculated from the dissolution energy of solids as given in Johnson et al. (1992) and Pourbaix (1966). The Pourbaix diagrams of SICEs are constructed by fixing the relative ratios of all chemical species except $\mathrm{H}$ and $\mathrm{O}$. For example, to generate the Pourbaix diagram of the $\mathrm{Na}_{3} \mathrm{Zr}_{2} \mathrm{Si}_{2} \mathrm{PO}_{12} \mathrm{NASICON}$, the $\mathrm{Na}: \mathrm{Zr}: \mathrm{Si}: \mathrm{P}$ ratio is fixed at 3:2:2:1, and the Pourbaix diagram at that composition is plotted as a function of $\mathrm{pH}$ and the applied voltage.

\section{CHEMISTRIES INVESTIGATED}

Twelve well-known Li-ion and Na-ion SICEs in a wide range of cation and anion chemistries are studied in this work. For each chemistry, we selected the most stable polymorph for analysis. While many metastable polymorphs are of greater interest due to their higher ionic conductivities, we argue that our analysis provides an upper limit to the free energy of decomposition in aqueous media, i.e., the metastable polymorph will be less stable (in a thermodynamic sense) than the specific phases investigated in this work. Furthermore, the relative energy differences between different polymorphs are on the order of $\sim 10 \mathrm{meV}$, about 2-3 orders magnitude smaller than the free-energy change of solvation. Our analysis is also limited to the undoped structures as we do not expect small dopant concentrations to alter the aqueous stability significantly. The SICEs studied in this work are as follows:

1. Oxides: The NAtrium SuperIonic CONductor (NASICON) and garnet families are two of the most widely explored oxide SICEs. In this work, we have studied the $\mathrm{Na}_{3} \mathrm{Zr}_{2} \mathrm{Si}_{2} \mathrm{PO}_{12}$ (Goodenough et al., 1976), $\mathrm{NaZr}_{2}\left(\mathrm{PO}_{4}\right)_{3}$, and $\mathrm{LiTi}_{2}\left(\mathrm{PO}_{4}\right)_{3}$ (Subramanian et al., 1986) members of the NASICON family, which allows us to study the effect of alkali ion and cation chemistry on aqueous stability. We have also selected the tetragonal $\mathrm{Li}_{7} \mathrm{La}_{3} \mathrm{Zr}_{2} \mathrm{O}_{12}$ (LLZO) (Murugan et al., 2007) garnet, which is the stable polymorph of the cubic garnet phase that is of interest because of its good ionic conductivity of $0.4 \mathrm{mS} /$ $\mathrm{cm}$ and excellent stability against Li metal anodes.

2. Sulfides: Sulfide SICEs have received wide attention recently due to their significantly higher ionic conductivities compared 


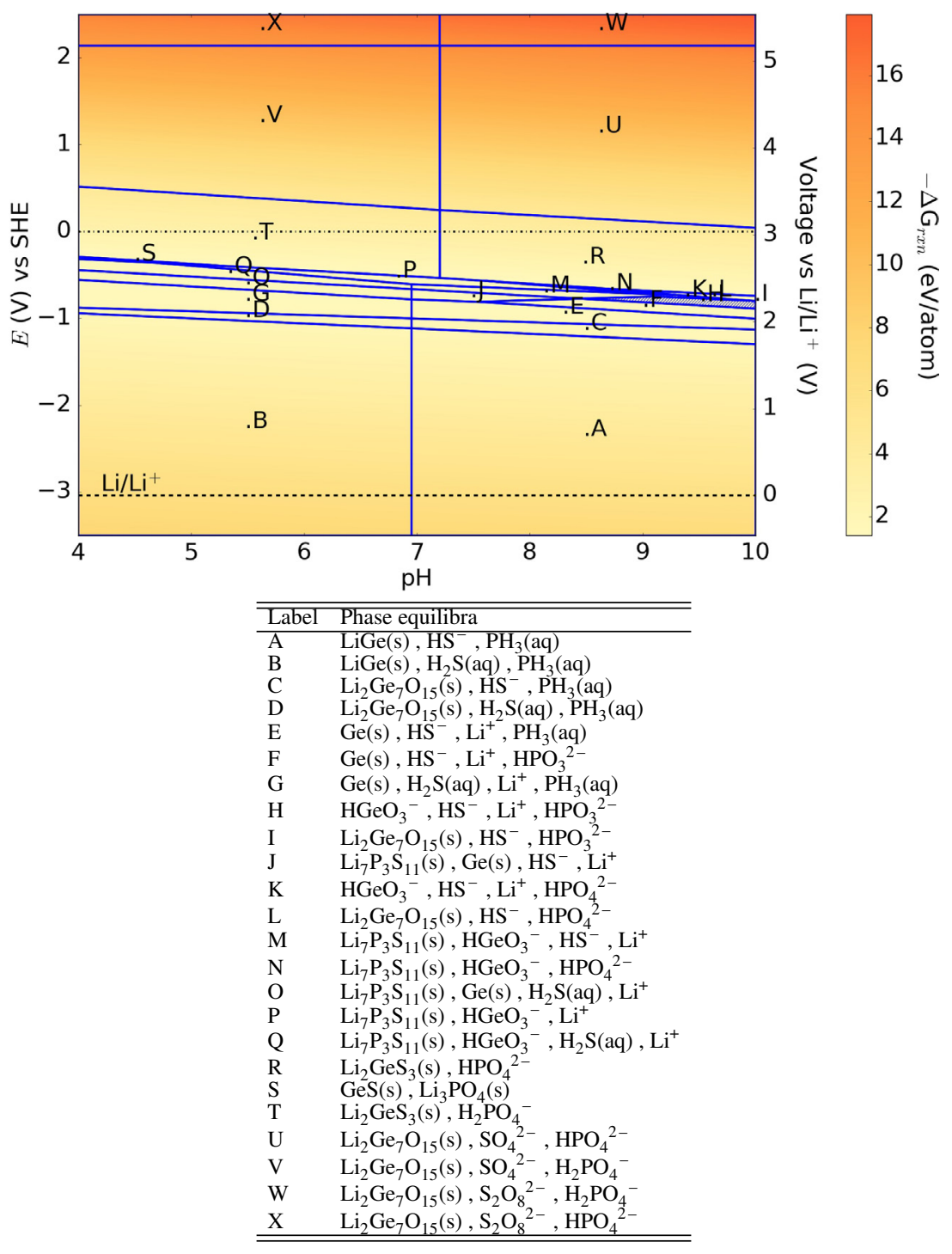

FIGURE 5 | Pourbaix diagram of $\mathrm{Li}_{10} \mathrm{GeP}_{2} \mathrm{~S}_{12}$. Shaded region indicates absence of any solid phase products.

to oxides. Among these sulfides, two of the most promising candidates are $\mathrm{Li}_{10} \mathrm{GeP}_{2} \mathrm{~S}_{12}$ (LGPS), which was reported by Kamaya et al. (2011) to have an ionic conductivity of $12 \mathrm{mS} /$ $\mathrm{cm}$, and $\mathrm{Li}_{7} \mathrm{P}_{3} \mathrm{~S}_{11}$ (Minami et al., 2007), which has the highest reported conductivity of $17 \mathrm{mS} / \mathrm{cm}$ thus far. We also included $\gamma$ - $\mathrm{Li}_{3} \mathrm{PS}_{4}$ (Liu et al., 2013), which is one of the parent structures of the widely used LiPON solid electrolyte, and tetragonal $\mathrm{Na}_{3} \mathrm{PS}_{4}\left(\mathrm{t}-\mathrm{Na}_{3} \mathrm{PS}_{4}\right)$, which is the stable polymorph of the cubic $\mathrm{Na}_{3} \mathrm{PS}_{4}$ SICE (Hayashi et al., 2012).

3. Halide-containing chemistries: Several halide-containing compounds have recently emerged as potential SICEs. The lithium-rich anti-perovskites (LRAP) (Zhao and Daemen, 2012) are a recently discovered class of SICEs, and we have included the $\mathrm{Li}_{3} \mathrm{OCl}$ and $\mathrm{Li}_{3} \mathrm{OBr}$ compounds in our analysis. We have also included both the oxide $\mathrm{Li}_{6} \mathrm{PO}_{5} \mathrm{Cl}$ and sulfide $\mathrm{Li}_{6} \mathrm{PS}_{5} \mathrm{Cl}$ members of the argyrodite family (Kong et al., 2010).

\section{RESULTS}

Using the above methodology, we have analyzed the aqueous stability of twelve well-known SICEs in a pH range of 4.0-10.0, i.e., from acidic to basic environments. The externally applied voltage is varied between $-3.5 \mathrm{~V}$ and $2.5 \mathrm{~V}$ (versus SHE), which encompasses an equivalent voltage range of -0.46 to $5.54 \mathrm{~V}$ versus $\mathrm{Li} / \mathrm{Li}^{+}(-3.04 \mathrm{~V}$ vs SHE) and -0.79 to $5.21 \mathrm{~V}$ versus $\mathrm{Na} /$ $\mathrm{Na}^{+}$(-2.71 V vs SHE) (Vanysek, 2011). In all Pourbaix diagrams, the corresponding alkali anode half-cell voltage is indicated for reference, and all aqueous ions other than $\mathrm{H}^{+}$are fixed at a molality of $10^{-6} \mathrm{~mol} / \mathrm{L}$. 


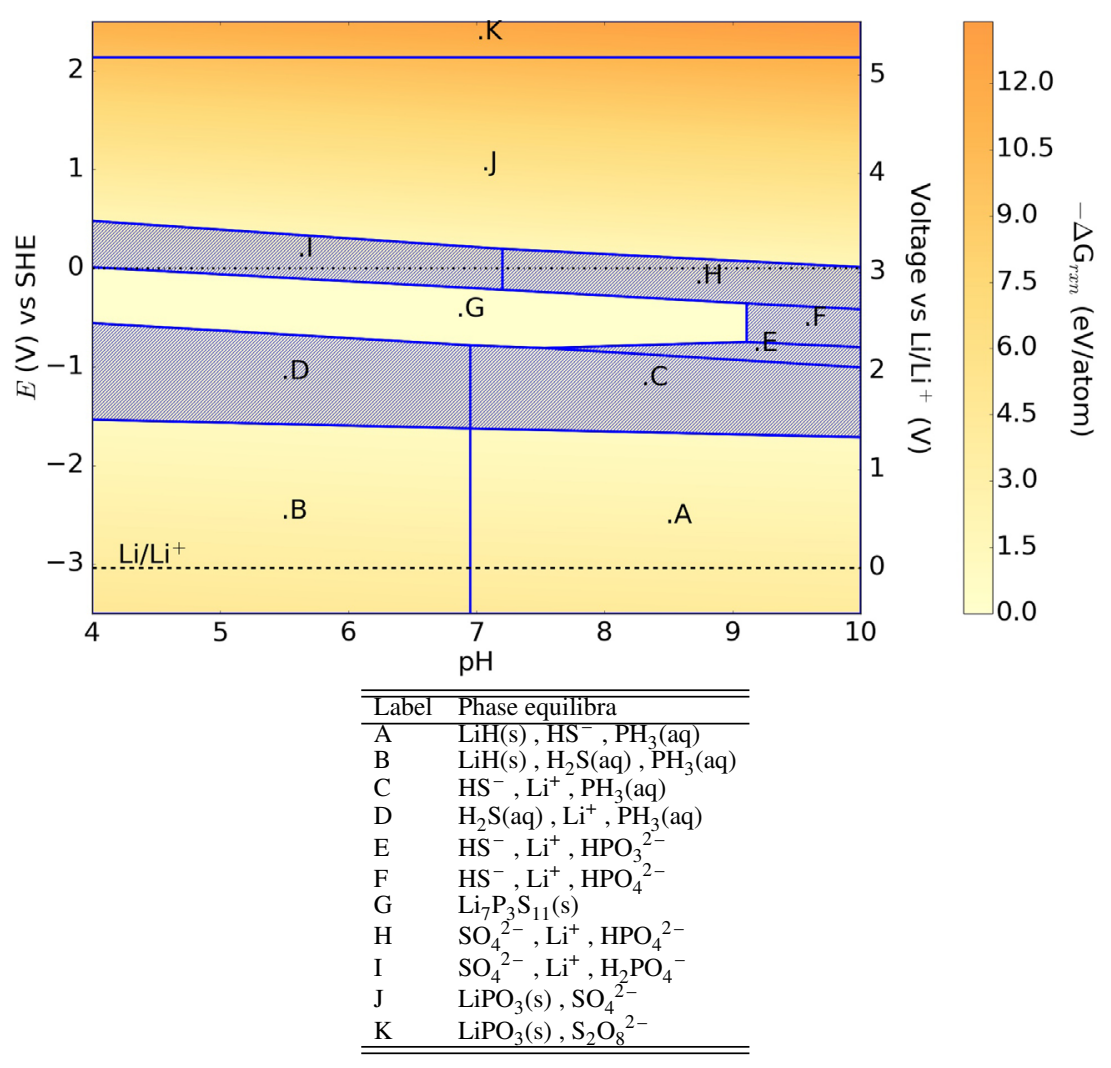

FIGURE 6 | Pourbaix diagram of $\mathrm{Li}_{7} \mathbf{P}_{3} \mathbf{S}_{11}$. Shaded region indicates absence of any solid phase products.

\subsection{Oxides}

\subsubsection{NASICON Na $3 Z_{2} \mathrm{Si}_{2} \mathrm{PO}_{12}, \mathrm{NaZr}_{2}\left(\mathrm{PO}_{4}\right)_{3}$, and} $\mathrm{LiTi}_{2}\left(\mathrm{PO}_{4}\right)_{3}$

The Pourbaix diagram of the $\mathrm{Na}_{3} \mathrm{Zr}_{2} \mathrm{Si}_{2} \mathrm{PO}_{12} \mathrm{NASICON}$ is shown in Figure 1. On exposure to neutral environments, the non-silicon version of NASICON:NaZr $2\left(\mathrm{PO}_{4}\right)_{3}$ is formed along with $\mathrm{ZrSiO}_{4}$ at $0 \mathrm{~V}$, materials known to be less ionically conductive compared to NASICON. This is qualitatively in good agreement with the experiments explaining the change in the surface morphology as well as the conductivity (Ahmad et al., 1987; Mauvy et al., 1999; Fuentes et al., 2001). Fuentes et al. (2001) attributes the change in surface morphology to the formation of hydronium NASICON, but positive identification has been found lacking. In the voltage range -3.5 to $-1 \mathrm{~V}$ (SHE), exposure to aqueous environments leads to formation of phosphine, which in gaseous form is known to be toxic and highly flammable. Otherwise, the Pourbaix diagram predicts that the NASICON forms solid insulating phases at high voltages. At low voltages, however, $\mathrm{ZrH}_{2}$, a metallic alloy (Bickel and Berlincourt, 1970), is predicted to be the only solid product formed, which may not protect the SICE against further reaction.

The free-energy change shows that NASICON is more stable at reducing environments than oxidizing environments, especially at neutral environments with $-\Delta G_{r x n} \leq 1 \mathrm{eV} /$ atom. In comparison, we observe that $\mathrm{NaZr}_{2}\left(\mathrm{PO}_{4}\right)_{3}$ (Figure 2) is more stable at neutral environments than $\mathrm{Na}_{3} \mathrm{Zr}_{2} \mathrm{Si}_{2} \mathrm{PO}_{12}$ (lower free-energy change), but corrodes in acidic environments.

$\mathrm{LiTi}_{2}\left(\mathrm{PO}_{4}\right)_{3}$ (LTP), which also crystallizes in the NASICON structure, is one of the most stable electrolytes at $0 \mathrm{~V}$ across the $\mathrm{pH}$ range with a $-\Delta G_{r x n} \leq 0.2 \mathrm{eV} /$ atom, as shown in Figure 3 . When exposed to aqueous environments at anodic voltages, it forms $\mathrm{LiH}, \mathrm{TiH}_{2}$, and phosphine gas. At voltages $>0 \mathrm{~V}$ (SHE), the solid products formed, such as $\mathrm{TiO}_{2}$ and $\mathrm{Li}_{2} \mathrm{O}_{2}$, can potentially provide a stable passivating layer. Acidity of the aqueous medium does not alter the composition of the passivating layers. The passivity predicted in the Pourbaix diagram explains the experimental observations that LTP is generally quite stable in aqueous environments (Zhang et al., 2008; Hasegawa et al., 2009). The same experiments also reported that exposure to $\mathrm{LiCl}$ and $\mathrm{LiOH}$, which are used in aqueous batteries, alters only the surface chemistry while the electrolyte material itself was stable. At anodic voltages, the tendency for $\mathrm{Ti}^{4+}$ to be reduced to $\mathrm{Ti}^{2+}$-forming $\mathrm{TiH}_{2}$ may account for the larger driving force toward decomposition. It should be noted that $\mathrm{TiH}_{2}$ (Ito et al., 2006) is metallic.

\subsubsection{Garnet $\mathrm{Li}_{7} \mathrm{La}_{3} \mathrm{Zr}_{2} \mathrm{O}_{12}$}

The Pourbaix diagram of garnet $\mathrm{Li}_{7} \mathrm{La}_{3} \mathrm{Zr}_{2} \mathrm{O}_{12}$ (Figure 4) shows that it is relatively stable in aqueous environments, with solid phases formed throughout the voltage range of interest. $\mathrm{Li}_{2} \mathrm{ZrO}_{3}$, formed at $0 \mathrm{~V}$ and oxidizing environments, is known to be a stable 
solid with low ionic conductivity. At anodic voltages $<-1 \mathrm{~V}$ (SHE), hydrides of $\mathrm{Li}, \mathrm{Zr}$, and $\mathrm{La}$ are formed.

Like LTAP, garnet SICEs have been explored for the role of a separator in aqueous electrolytes with Li metal anodes (Imanishi et al., 2014). Similar to the NASICONs, we find that the acidity of the aqueous medium does not significantly alter the products formed. Also, the low free-energy change $(\leq 1 \mathrm{eV} /$ atom at $0 \mathrm{~V})$ throughout the $\mathrm{pH}$ range shows that the garnet is relatively stable in aqueous environments, consistent with previous experimental observations (Murugan et al., 2007; Shimonishi et al., 2011).

\subsection{Sulfides}

\subsection{1. $\mathrm{Li}_{10} \mathrm{GeP}_{2} \mathrm{~S}_{12}$ (LGPS)}

From Figure 5, we may observe that the $\mathrm{Li}_{10} \mathrm{GeP}_{2} \mathrm{~S}_{12}$ (LGPS) (Kamaya et al., 2011) superionic conductor is predicted to form solid phases throughout the entire voltage range. At $0 \mathrm{~V}$ (SHE) and oxidizing environments, $\mathrm{Li}_{2} \mathrm{Ge}_{7} \mathrm{O}_{15}$ is one of the products formed, which can potentially form a good passivation layer even though it has much lower ionic conductivity compared to LGPS. However, either $\mathrm{LiGe}$ or $\mathrm{Ge}$ are formed at voltages $\leq-1 \mathrm{~V}$ (SHE), which being poor electronic insulators, may not passivate the SICE against further reaction. Between voltages $\pm 0.5 \mathrm{~V}$ (SHE), $\mathrm{Li}_{2} \mathrm{GeS}_{3}$ is formed which has a reasonable ionic conductivity of
$0.1 \mathrm{mS} / \mathrm{cm}$ (Seo and Martin, 2011). As with other phosphorous containing compounds, phosphine gas is one of the predicted products at voltages $\leq 0 \mathrm{~V}(\mathrm{SHE})$.

Though solid phases are generally formed for LGPS throughout the $\mathrm{pH}$ and voltage range of interest, we find that the driving force for the formation of these products is generally higher than for the oxide phases. Unlike the NASICON and garnet, LGPS shows greater driving force toward oxidation rather than reduction.

\subsection{2. $\mathrm{Li}_{7} \mathrm{P}_{3} \mathrm{~S}_{11}$}

In contrast to $\mathrm{Li}_{10} \mathrm{GeP}_{2} \mathrm{~S}_{12}$, the $\mathrm{Li}_{7} \mathrm{P}_{3} \mathrm{~S}_{11}$ (Minami et al., 2007) glass-ceramic is predicted to be significantly less stable in aqueous environments. There are large $\mathrm{E}-\mathrm{pH}$ regions where no solid phases are stable (shaded regions in Figure 6). The potentially passivating $\mathrm{LiPO}_{3}$ phase is formed at cathodic voltages of $5 \mathrm{~V}$ (vs SHE), while hydrides and phosphine are formed at anodic voltages $\leq-1.5 \mathrm{~V}$ (SHE), similar to other SICEs.

\subsection{3. $\mathrm{t}-\mathrm{Na}_{3} \mathrm{PS}_{4}$ and $\gamma-\mathrm{Li}_{3} \mathrm{PS}_{4}$}

$\mathrm{M}_{3} \mathrm{PS}_{4}(\mathrm{M}=\mathrm{Na}$ and $\mathrm{Li})$ also belongs to the $\mathrm{M}_{2} \mathrm{~S}-\mathrm{P}_{2} \mathrm{~S}_{5}$ glass-ceramic system. The qualitative features of their Pourbaix diagrams (Figures 7 and 8) are very similar to that of $\mathrm{Li}_{7} \mathrm{P}_{3} \mathrm{~S}_{11}$, with large $\mathrm{E}-\mathrm{pH}$ regions where no solid phases are stable. Phosphates and

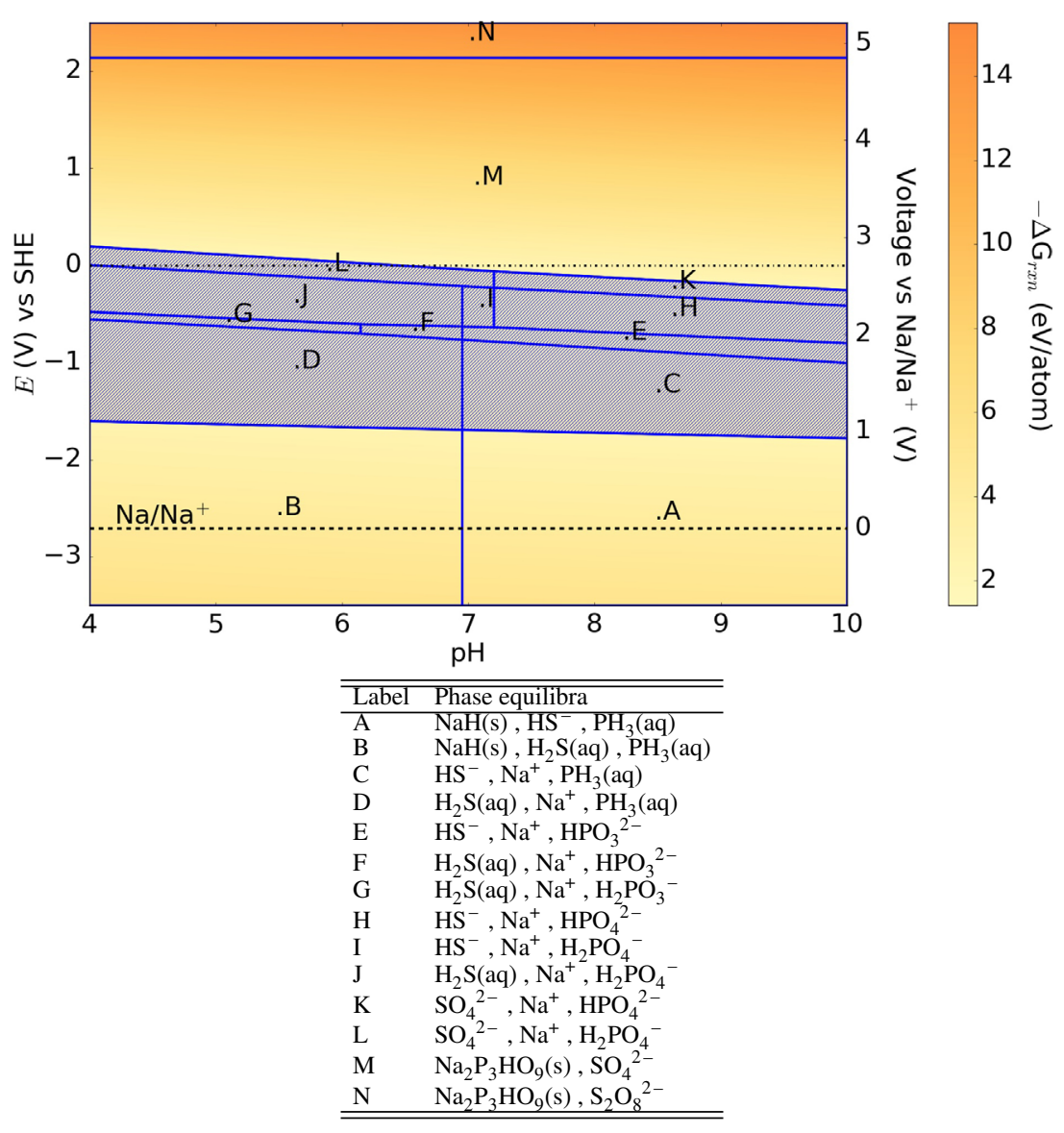

FIGURE 7 | Pourbaix diagram of t- $\mathrm{Na}_{3} \mathrm{PS}_{4}$. Shaded region indicates absence of any solid phase products. 


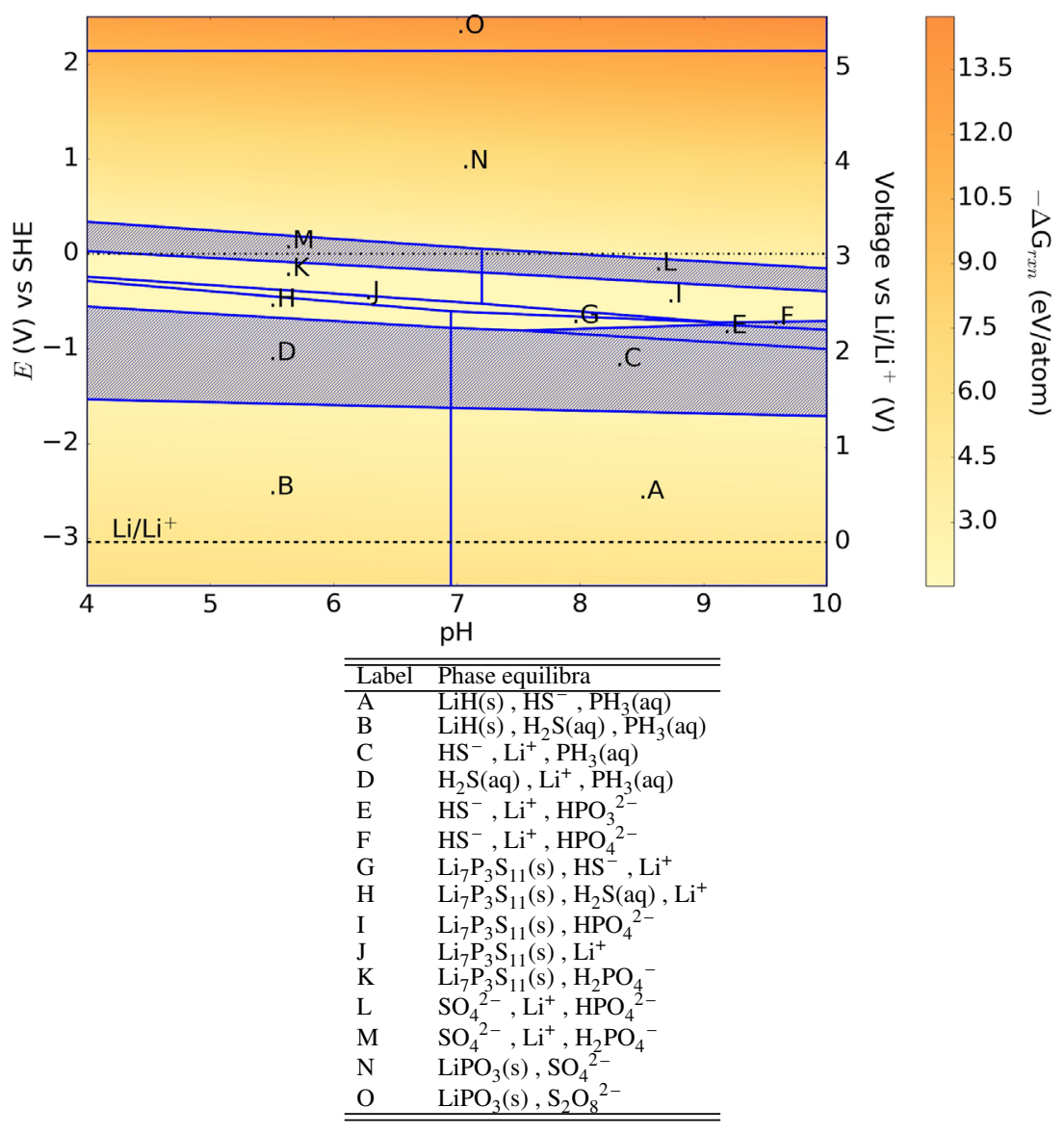

FIGURE 8 | Pourbaix diagram of $\boldsymbol{\gamma}-\mathrm{Li}_{3} \mathrm{PS}_{4}$. Shaded region indicates absence of any solid phase products.

hydrated phosphates are generally formed at cathodic voltages, while hydrides are formed at anodic voltages.

\subsection{Halide-Containing Chemistries 4.3.1. Lithium-Rich Anti-Perovskites (LRAP) $\mathrm{Li}_{3} \mathrm{OCl}$ and $\mathrm{Li}_{3} \mathrm{OBr}$}

Figures 9 and $\mathbf{1 0}$ show the Pourbaix diagrams of the $\mathrm{Li}_{3} \mathrm{OCl}$ and $\mathrm{Li}_{3} \mathrm{OBr}$ anti-perovskites, respectively. In general, the anti-perovskites are predicted to be unstable in aqueous environments with large regions where no solid phases are formed. Lithium peroxide $\mathrm{Li}_{2} \mathrm{O}_{2}$ is predicted to form at voltages $\geq 1 \mathrm{~V}$ (SHE), while $\mathrm{LiH}$ is predicted to form at voltages $\leq-1.5 \mathrm{~V}$ (SHE). Between the two anion chemistries, the key difference is in the free-energy change of reaction. The chloride is predicted to have a higher free-energy change, i.e., larger driving force for decomposition, compared to the bromide. Nevertheless, these free-energy changes are much smaller in magnitude compared to the sulfides, which suggest that the LRAPs are less reactive compared to the sulfides in aqueous media.

\subsubsection{Argyrodites $\mathrm{Li}_{6} \mathrm{PO}_{5} \mathrm{Cl}$ and $\mathrm{Li}_{6} \mathrm{PS}_{5} \mathrm{Cl}$}

The Pourbaix diagram of the oxide-argyrodite $\mathrm{Li}_{6} \mathrm{PO}_{5} \mathrm{Cl}$ (Figure 11) has generally similar features as that of the LRAPs, with large E-pH regions containing no stable solid phases. Somewhat surprisingly, we find that the sulfur-argyrodite $\mathrm{Li}_{6} \mathrm{PS}_{5} \mathrm{Cl}$ may form a passivating layer of $\mathrm{Li}_{7} \mathrm{P}_{3} \mathrm{~S}_{11}$ at $0 \mathrm{~V}$ (SHE) as shown in Figure 12. A computational study on the sulfurargyrodites $\left(\mathrm{Li}_{6} \mathrm{PS}_{5} \mathrm{X}\right)$ by Chen et al. (2015) hypothesized the formation of $\mathrm{LiX}, \mathrm{LiOH}, \mathrm{H}_{2} \mathrm{~S}$, and $\mathrm{Li}_{3} \mathrm{PO}_{4}$ on hydrolysis with predicted decomposition energies of the order of $0.3 \mathrm{eV} /$ atom. Our results predict decomposition energies ranging $1.5-12 \mathrm{eV} /$ atom with a range of both solid and aqueous products formed across the $\mathrm{E}-\mathrm{pH}$ range.

\section{DISCUSSION}

In this work, we investigated the aqueous stability of twelve wellknown SICE chemistries using a Pourbaix diagram formalism. None of the SICEs investigated are found to be completely nonreactive on exposure to moisture. However, the decomposition of an electrolyte itself is not necessarily fatal to the electrochemical performance. After all, the organic solvents, such as ethylene carbonate and dimethylcarbonate, are unstable with respect to reduction by Li metal. The key is whether a good passivation layer can be formed that will protect the SICE against further 


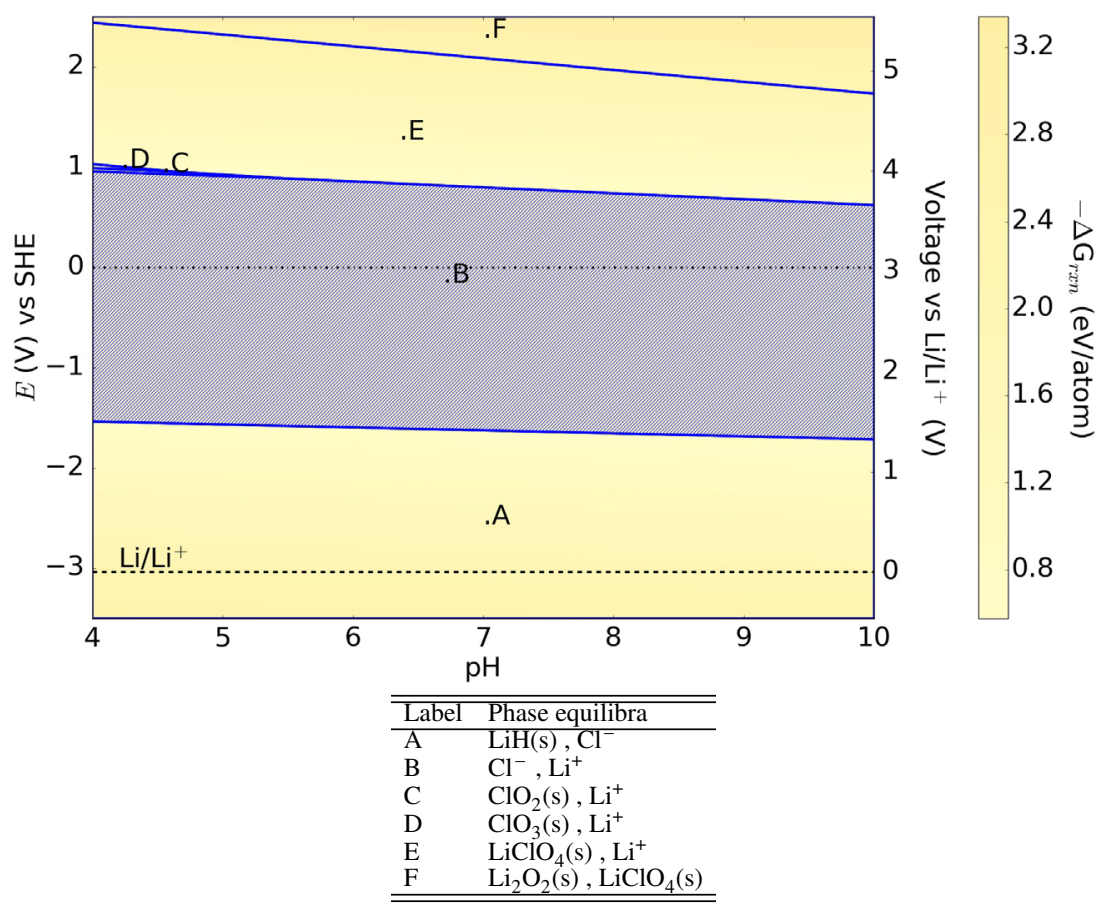

FIGURE 9 | Pourbaix diagram of $\mathrm{Li}_{3} \mathrm{OCl}$. Shaded region indicates absence of any solid phase products.

reaction and still provide a reasonable pathway for alkali-ion transport.

Our broad findings are in general agreement with previous experimental studies and expected behavior of chemistries, i.e., that sulfide and halide-containing SICEs are less stable under aqueous media than oxide SICEs, with larger driving forces to oxidize at cathodic (high) voltages vs SHE. However, we find that there are significant variations in stability even within the same anion chemistry. For instance, comparing the $\mathrm{Na}_{3} \mathrm{Zr}_{2} \mathrm{Si}_{2} \mathrm{PO}_{12}$ and $\mathrm{NaZr}_{2}\left(\mathrm{PO}_{4}\right)_{3}$ NASICONs, we find that the former is more stable, particularly under acidic environments at high voltages, due to the presence of $\mathrm{Si}$ which promotes formation of solid silicate phases. Indeed, this observation suggests that the choice of cation (other than the alkali ion) may be a possible means to tune the phases formed at various E-pH. Another example can be seen by comparing the Pourbaix diagrams of LGPS, $\mathrm{Li}_{7} \mathrm{P}_{3} \mathrm{~S}_{11}$, and $\gamma-\mathrm{Li}_{3} \mathrm{PS}_{4}$. Although all the three materials are thiophosphates, the presence of Ge in LGPS results in the formation of stable solid phases across most of the investigated $\mathrm{E}-\mathrm{pH}$ range.

In rechargeable alkali batteries, an ultimate goal is the use of a metal anode, which would yield significant increases in energy density over traditional carbon-based (graphitic for Li and hard carbons for $\mathrm{Na}$ ) anodes. However, the inherent reactivity of the alkali metal, as well as the potential for dendrite formation during plating (for $\mathrm{Li}$ ), has thus far pose a great challenge in the real-world applications. One potential strategy of addressing both issues is to use a separator to protect the alkali metal, as well as act as a barrier against dendrite formation. Indeed, the two common SICEs explored for this purpose, $\mathrm{LiTi}_{2}\left(\mathrm{PO}_{4}\right)_{3}$ and garnet LLZO (Zhang et al., 2008; Imanishi et al., 2014), are predicted to have relatively good stability in aqueous media. The garnet LLZO, in particular, is remarkable for its relative lack of reactivity across wide voltage and $\mathrm{pH}$ ranges, and low driving forces for decomposition.

It should be noted that the analysis presented is a purely thermodynamic one, and no kinetic factors are taken into account. Furthermore, while the lack of any stable solid phase would certainly preclude the possibility of passivation in a particular E-pH region, the existence of stable solid phases does not necessarily mean that a stable passivation layer will be formed. Ultimately, whether a solid phase can form a useful passivation layer depends on its morphology upon formation, its electronic conductivity, and its ionic conductivity. Nevertheless, we believe this work provides useful predictions of the phase equilibria at various $\mathrm{E}-\mathrm{pH}$ and a quantification of the thermodynamic driving forces for reaction. These predictions can, and hopefully would be, validated against comprehensive experimental studies of SICEs in aqueous media.

\section{CONCLUSION}

To conclude, we have analyzed and compared the aqueous stability of twelve SICEs using a Pourbaix diagram formalism. In general, the predicted relative stabilities of the SICEs are in line with previous experimental results, where available, and expected behavior of chemistries. We find that the anion chemistry is a primary determinant of aqueous stability, though 


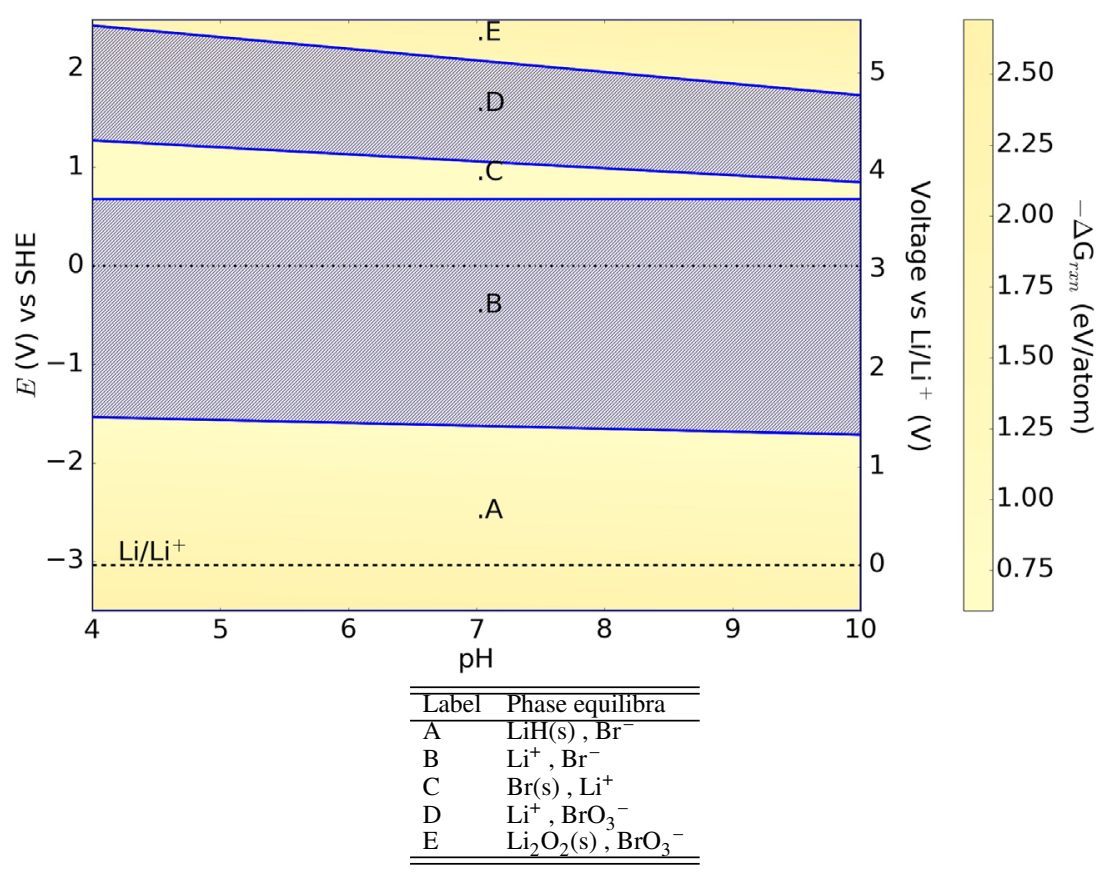

FIGURE 10 | Pourbaix diagram of $\mathrm{Li}_{3} \mathrm{OBr}$. Shaded region indicates absence of any solid phase products.

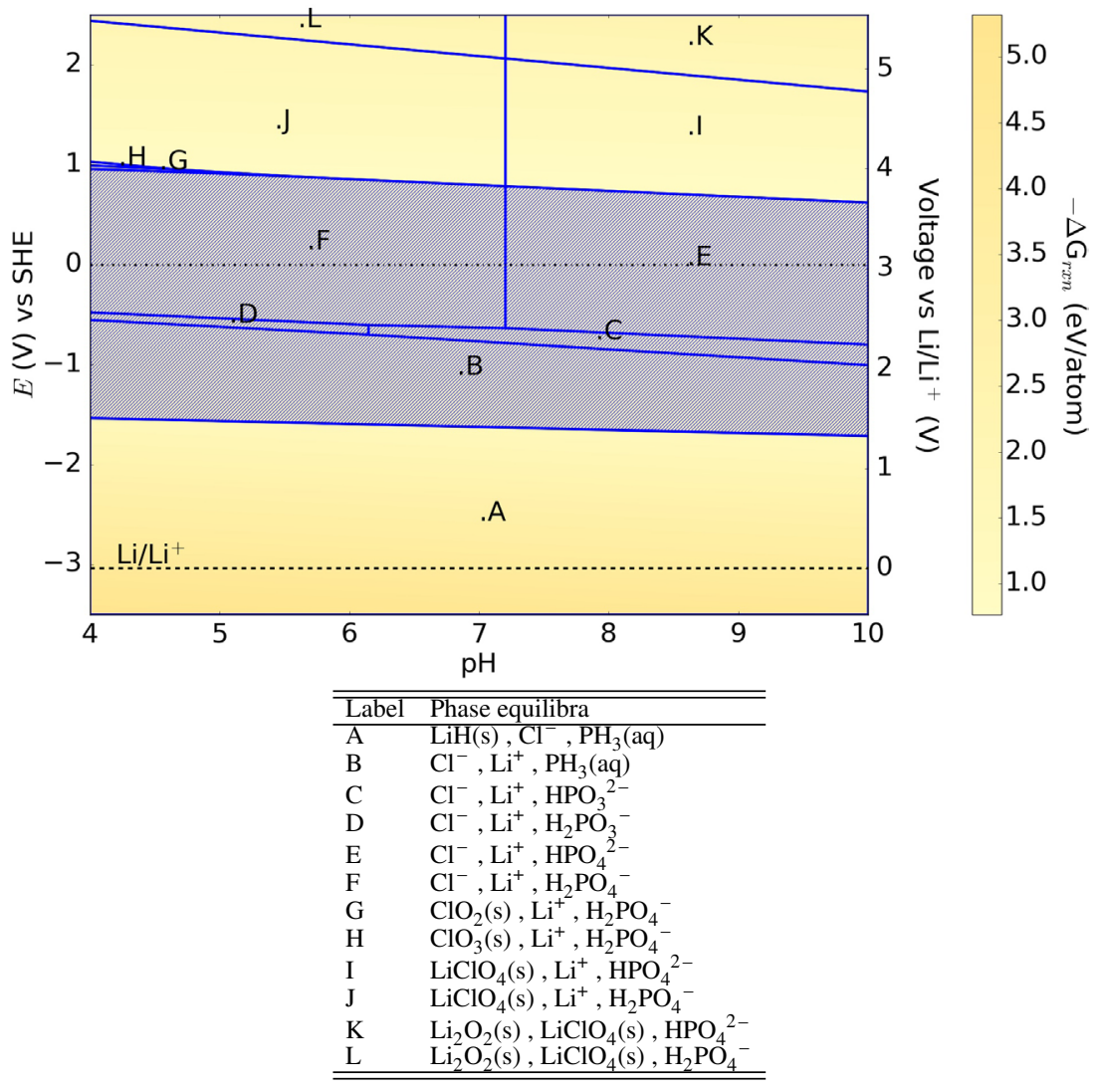

FIGURE 11 | Pourbaix diagram of $\mathrm{Li}_{6} \mathbf{P O}_{5} \mathbf{C l}$. Shaded region indicates absence of any solid phase products. 


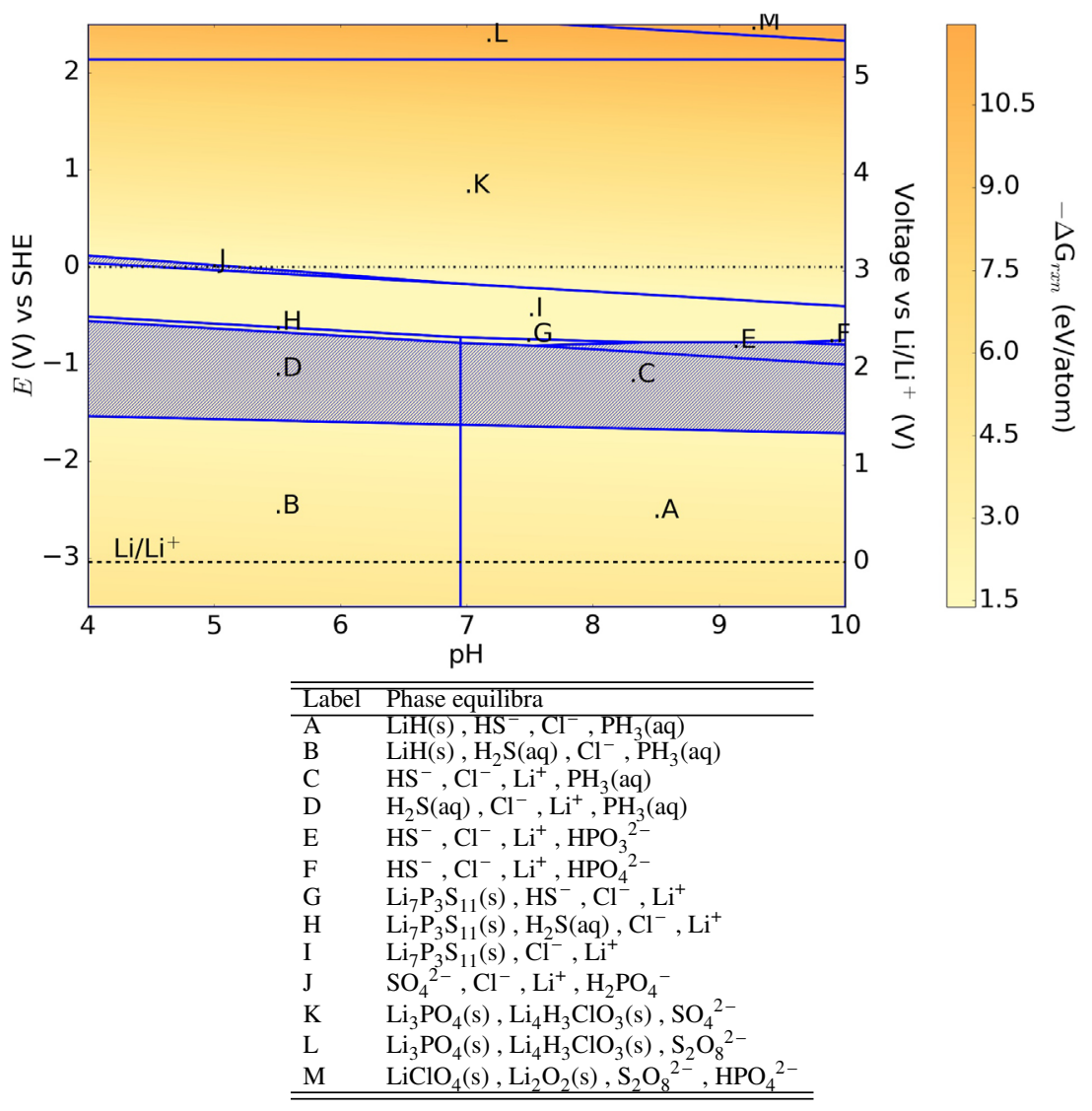

FIGURE 12 | Pourbaix diagram of $\mathrm{Li}_{6} \mathbf{P S}_{5} \mathbf{C l}$. Shaded region indicates absence of any solid phase products.

careful tuning of the cation chemistry can alter the solid phases formed and is a potential means of tuning SICEs for specific applications. Beyond SICEs, the first-principles approach presented here can be similarly applied to other technological applications, where aqueous stability of a material is a design concern.

\section{AUTHOR CONTRIBUTIONS}

BR designed and implemented the study on aqueous stability of alkali superionic conductors. SO is the principal investigator of this project and supervised the conceptualization and

\section{REFERENCES}

Ahmad, A., Wheat, T., Kuriakose, A., Canaday, J., and McDonald, A. (1987). Dependence of the properties of NASICONS on their composition and processing. Solid State Ionics 24, 89-97. doi:10.1016/0167-2738(87)90070-1

Aono, H., Sugimoto, E., Sadaoka, Y., Manaka, N., and Adachi, G. (1990). Ionic conductivity of solid electrolytes based on lithium titanium phosphate. J. Electrochem. Soc. 137, 1023-1027. doi:10.1149/1.2086597

Bickel, P. W., and Berlincourt, T. G. (1970). Electrical properties of hydrides and deuterides of zirconium. Phys. Rev. B 2, 4807-4813. doi:10.1103/ PhysRevB.2.4807 implementation. Both authors made equal contribution toward analysis of results and drafting the manuscript.

\section{FUNDING}

This work was supported by the National Science Foundation's Designing Materials to Revolutionize and Engineer our Future (DMREF) program under Grant No. 1436976. Some of the computations in this work were performed using the Extreme Science and Engineering Discovery Environment (XSEDE), which is supported by National Science Foundation grant number ACI- 1053575.

Chen, H. M., Maohua, C., and Adams, S. (2015). Stability and ionic mobility in argyrodite-related lithium-ion solid electrolytes. Phys. Chem. Chem. Phys. 17, 16494-16506. doi:10.1039/c5cp01841b

Deng, Z., Wang, Z., Chu, I.-H., Luo, J., and Ong, S. P. (2016). Elastic properties of alkali superionic conductor electrolytes from first principles calculations. J. Electrochem. Soc. 163, A67-A74. doi:10.1149/2.0061602jes

Doughty, D. H., and Pesaran, A. A. (2012). Vehicle Battery Safety Roadmap Guidance. Golden: National Renewable Energy Laboratory.

Fuentes, R. O., Figueiredo, F., Marques, F. M. B., and Franco, J. I. (2001). Reaction of NASICON with water. Solid State Ionics. 139, 309-314. doi:10.1016/ S0167-2738(01)00683-X 
Goodenough, J. B., Hong, H. Y.-P., and Kafalas, J. A. (1976). Fast Na/+/ion transport in skeleton structures. Mater. Res. Bull. 11, 203-220. doi:10.1016/0025-5408(76)90077-5

Hasegawa, S., Imanishi, N., Zhang, T., Xie, J., Hirano, A., Takeda, Y., et al. (2009). Study on lithium/air secondary batteries-stability of NASICON-type lithium ion conducting glass-ceramics with water. J. Power Sources 189, 371-377. doi:10.1016/j.jpowsour.2008.08.009

Hayashi, A., Noi, K., Sakuda, A., and Tatsumisago, M. (2012). Superionic glassceramic electrolytes for room-temperature rechargeable sodium batteries. Nat. Commun. 3, 856. doi:10.1038/ncomms 1843

Imanishi, N., Matsui, M., Takeda, Y., and Yamamoto, O. (2014). Lithium ion conducting solid electrolytes for aqueous lithium-air batteries. Electrochemistry 82, 938-945. doi:10.5796/electrochemistry.82.938

Ito, M., Setoyama, D., Matsunaga, J., Muta, H., Kurosaki, K., Uno, M., et al. (2006). Electrical and thermal properties of titanium hydrides. J. Alloys Comp. 420, 25-28. doi:10.1016/j.jallcom.2005.10.032

Jain, A., Ong, S. P., Hautier, G., Chen, W., Richards, W. D., Dacek, S., et al. (2013). Commentary: the materials project: a materials genome approach to accelerating materials innovation. APL Mater. 1, 011002. doi: $10.1063 / 1.4812323$

Johnson, W. J., Oelkers, H. E., and Helgeson, C. H. (1992). SUPCRT92: a software package for calculating the standard molal thermodynamic properties of minerals, gases, aqueous species, and reactions from 1 to 5000 bar and 0 to $1000 \mathrm{C}$. Comput. Geosci. 18, 899-947. doi:10.1016/0098-3004(92)90029-Q

Kamaya, N., Homma, K., Yamakawa, Y., Hirayama, M., Kanno, R., Yonemura, M., et al. (2011). A lithium superionic conductor. Nat. Mater. 10, 682-686. doi: $10.1038 /$ nmat3066

Kanno, R., Hata, T., Kawamoto, Y., and Irie, M. (2000). Synthesis of a new lithium ionic conductor, thio-LISICON - lithium germanium sulfide system. Solid State Ionics. 130, 97-104. doi:10.1016/S0167-2738(00)00277-0

Kong, S. T., Deiseroth, H. J., Maier, J., Nickel, V., Weichert, K., and Reiner, C. (2010). $\mathrm{Li}_{6} \mathrm{PO}_{5} \mathrm{Br}$ and $\mathrm{Li}_{6} \mathrm{PO}_{5} \mathrm{Cl}$ : the first lithium-oxide-argyrodites. Z. Anorg. Allg. Chem. 636, 1920-1924. doi:10.1002/zaac.201000121

Kresse, G., and Furthmüller, J. (1996). Efficient iterative schemes for ab initio total-energy calculations using a plane-wave basis set. Phys. Rev. B Condens. Matter 54, 11169-11186. doi:10.1103/PhysRevB.54.11169

Kubaschewski, O., Alcock, C. B., and Spencer, P. J. (1993). Materials Thermochemistry. New York: Pergamon Press.

Liu, T., Leskes, M., Yu, W., Moore, A. J., Zhou, L., Bayley, P. M., et al. (2015). Cycling $\mathrm{Li}-\mathrm{O}_{2}$ batteries via $\mathrm{LiOH}$ formation and decomposition. Science 350, 530-533. doi:10.1126/science.aac7730

Liu, Z., Fu, W., Payzant, E. A., Yu, X., Wu, Z., Dudney, N. J., et al. (2013). Anomalous high ionic conductivity of nanoporous beta- $\mathrm{Li}_{3} \mathrm{PS}_{4}$. J. Am. Chem. Soc. 135, 975-978. doi:10.1021/ja3110895

Luo, J.-Y., Cui, W.-J., He, P., and Xia, Y.-Y. (2010). Raising the cycling stability of aqueous lithium-ion batteries by eliminating oxygen in the electrolyte. Nat. Chem. 2, 760-765. doi:10.1038/nchem.763

Ma, C., Rangasamy, E., Liang, C., Sakamoto, J., More, K. L., and Chi, M. (2015). Excellent stability of a lithium-ion-conducting solid electrolyte upon reversible $\mathrm{Li}+/ \mathrm{H}+$ exchange in aqueous solutions. Angew. Chem. Int. Ed. Engl. 127, 131-135. doi:10.1002/ange.201500056

Mauvy, F., Siebert, E., and Fabry, P. (1999). Reactivity of NASICON with water and interpretation of the detection limit of a NASICON based $\mathrm{Na}+$ ion selective electrode. Talanta 48, 293-303. doi:10.1016/S0039-9140(98)00234-3

Minami, K., Mizuno, F., Hayashi, A., and Tatsumisago, M. (2007). Lithium ion conductivity of the $\mathrm{Li}_{2} \mathrm{SP}_{2} \mathrm{~S}_{5}$ glass-based electrolytes prepared by the melt quenching method. Solid State Ionics 178, 837-841. doi:10.1016/j.ssi.2007.03.001

Mizuno, F., Hayashi, A., Tadanaga, K., and Tatsumisago, M. (2005). New, highly ion-conductive crystals precipitated from $\mathrm{Li}_{2} \mathrm{~S}_{-} \mathrm{P}_{2} \mathrm{~S}_{5}$ glasses. Adv. Mater. Weinheim 17, 918-921. doi:10.1002/adma.200401286
Murugan, R., Thangadurai, V., and Weppner, W. (2007). Fast lithium ion conduction in garnet-type $\mathrm{Li}(7) \mathrm{La}(3) \mathrm{Zr}(2) \mathrm{O}(12)$. Angew. Chem. Int. Ed. Engl. 46, 7778-7781. doi:10.1002/anie.200701144

Ong, S. P., Richards, W. D., Jain, A., Hautier, G., Kocher, M., Cholia, S., et al. (2013). Python Materials Genomics (pymatgen): a robust, open-source python library for materials analysis. Comput. Mater. Sci. 68, 314-319. doi:10.1016/j. commatsci.2012.10.028

Perdew, J., Burke, K., and Ernzerhof, M. (1996). Generalized gradient approximation made simple. Phys. Rev. Lett. 77, 3865-3868. doi:10.1103/PhysRevLett.77.3865

Persson, K. A., Waldwick, B., Lazic, P., and Ceder, G. (2012). Prediction of solid-aqueous equilibria: scheme to combine first-principles calculations of solids with experimental aqueous states. Phys. Rev. B 85, 235438. doi:10.1103/ PhysRevB.85.235438

Pourbaix, M. (1966). Atlas of Electrochemical Equilibria in Aqueous Solutions. Oxford: Pergamon Press.

Rangasamy, E., Wolfenstine, J., and Sakamoto, J. (2012). The role of Al and Li concentration on the formation of cubic garnet solid electrolyte of nominal composition $\mathrm{Li}_{7} \mathrm{La}_{3} \mathrm{Zr}_{2} \mathrm{O}_{12}$. Solid State Ionics 206, 28-32. doi:10.1016/j. ssi.2011.10.022

Rao, R. P., and Adams, S. (2011). Studies of lithium argyrodite solid electrolytes for all-solid-state batteries. Phys Status Solidi A Appl. Mater. 208, 1804-1807. doi:10.1002/pssa.201001117

Richards, W. D., Miara, L. J., Wang, Y., Kim, J. C., and Ceder, G. (2016). Interface stability in solid-state batteries. Chem. Mater. 28, 266-273. doi:10.1021/acs. chemmater.5b04082

Seo, I., and Martin, S. W. (2011). Preparation and characterization of fast ion conducting lithium thio-germanate thin films grown by RF magnetron sputtering. J. Electrochem. Soc. 158, A465. doi:10.1149/1.3552927

Shimonishi, Y., Toda, A., Zhang, T., Hirano, A., Imanishi, N., Yamamoto, O., et al. (2011). Synthesis of garnet-type $\mathrm{Li}_{7-\mathrm{x}} \mathrm{La}_{3} \mathrm{Zr}_{2} \mathrm{O}_{12-1 / 2 \mathrm{x}}$ and its stability in aqueous solutions. Solid State Ionics 183, 48-53. doi:10.1016/j.ssi.2010.12.010

Subramanian, M., Subramanian, R., and Clearfield, A. (1986). Lithium ion conductors in the system $\mathrm{AB}(\mathrm{IV}) 2(\mathrm{PO} 4) 3(\mathrm{~B}=\mathrm{Ti}, \mathrm{Zr}$ and $\mathrm{Hf})$. Solid State Ionics 18-19, 562-569. doi:10.1016/0167-2738(86)90179-7

Vanysek, P. (2011). "Electrochemical series," in Handbook of Chemistry and Physics, ed. W. M. Haynes, 92nd Edn (London: CRC Press), 5-80-5-89.

Visco, S. J., and Chu, M.-Y. (2000). Protective Coatings for Negative Electrodes. Patent No: US 6025094 A

$\mathrm{Xu}, \mathrm{K}$. (2014). Electrolytes and interphases in Li-ion batteries and beyond. Chem. Rev. 114, 11503-11618. doi:10.1021/cr500003w

Zhang, T., Imanishi, N., Hasegawa, S., Hirano, A., Xie, J., Takeda, Y., et al. (2008). Li polymer electrolyte water stable lithium-conducting glass ceramics composite for lithium-air secondary batteries with an aqueous electrolyte. J. Electrochem. Soc. 155, A965. doi:10.1149/1.2990717

Zhao, Y., and Daemen, L. L. (2012). Superionic conductivity in lithium-rich anti-perovskites. J. Am. Chem. Soc. 134, 15042-15047. doi:10.1021/ja305709z

Zhu, Y., He, X., and Mo, Y. (2016). First principles study on electrochemical and chemical stability of the solid electrolyte-electrode interfaces in all-solid-state Li-ion batteries. J. Mater. Chem. A 4, 3253-3266. doi:10.1039/C5TA08574H

Conflict of Interest Statement: The authors declare that the research was conducted in the absence of any commercial or financial relationships that could be construed as a potential conflict of interest.

Copyright (c) 2016 Radhakrishnan and Ong. This is an open-access article distributed under the terms of the Creative Commons Attribution License (CC BY). The use, distribution or reproduction in other forums is permitted, provided the original author(s) or licensor are credited and that the original publication in this journal is cited, in accordance with accepted academic practice. No use, distribution or reproduction is permitted which does not comply with these terms. 